\title{
Determinismo biológico e as neurociências no caso do transtorno de déficit de atenção com hiperatividade
}

| ${ }^{1}$ Fabiola Stolf Brzozowski, 2 Sandra Caponi I

Resumo: Nosso objetivo é refletir de que forma as neurociências podem ser fortemente reducionistas quando tentam explicar comportamentos somente com base em processos cerebrais, e usamos como exemplo o caso do transtorno de déficit de atenção com hiperatividade (TDAH). O reducionismo ao qual nos referimos, também chamado determinismo biológico ou neurogenético, na questão das neurociências, é o epistemológico, ou seja, aquele que tenta explicar um problema complexo apenas por algumas de suas partes, desconsiderando outros fatores, tais como sociais e culturais. Como o TDAH atualmente é descrito essencialmente como uma doença cerebral, aplicamos um modelo de sequência redutora defeituosa para o determinismo neurogenético proposto por Steven Rose, que inclui: objetivação, aglomeração arbitrária, quantificação improcedente, crença na normalidade estatística, localização ilegítima, causalidade fora de lugar, classificação dicotômica de causas genéticas e ambientais e a confusão de metáfora com homologia. A vida é um fenômeno complexo e está relacionada com aspectos biológicos e sociais. Dessa forma, explicações sobre ela são adequadas somente quando levam em conta esses dois aspectos. Sugerimos, dessa forma, que parte das neurociências utiliza explicações reducionistas para várias condiçôes mentais classificadas como doenças, incluindo o TDAH.

> Palavras-chave: neurociência; transtorno de déficit de atenção com hiperatividade; reducionismo; determinismo biológico; determinismo neurogenético.

\footnotetext{
1 Programa de Pós-Graduação em Saúde Coletiva da Universidade Federal de Santa Catarina. Endereço eletrônico: fabijerzy@yahoo.com

2 Departamento de Sociologia e Ciências Políticas da Universidade Federal de Santa Catarina. Endereço eletrônico: sandracaponi@gmail.com
} 


\section{Introdução}

O objetivo das neurociências é compreender os mecanismos celulares e moleculares do funcionamento cerebral a fim de que, no longo prazo, seja possível agir sobre o cérebro para modificar estados mentais (EHRENBERG, 2009). Engloba as disciplinas biológicas que estudam o sistema nervoso, mas também disciplinas que buscam a explicação sobre comportamentos, cognição e regulação orgânica. Por isso, nas neurociências, há uma junção entre o social, o cerebral e o mental. As disciplinas que hoje formam as neurociências tinham inicialmente como objetivo o estudo do movimento, dos sentidos (tais como visão e audição), da aprendizagem e das doenças neurológicas (por exemplo, Alzheimer e Parkinson). A partir da década de 1980, as doenças neurológicas e as doenças mentais, além das emoçōes, comportamentos e alguns sentimentos morais, passaram a ser considerados como pertencentes a um mesmo conjunto de transtornos (EHRENBERG, 2009).

Joelle Abi-Rached e Nikolas Rose (2010) afirmam que, apesar de conhecermos estudos sobre o cérebro desde a Antiguidade, foi na década de 1960 que ocorreu uma "quebra" na história das ciências do cérebro. A hibridização de diferentes disciplinas, práticas e conhecimentos sobre o cérebro, mente e comportamento e a introdução de uma abordagem molecular predominantemente reducionista são as principais características dos estudos em neurociência atualmente. Os autores chamam essa mudança de "olhar neuromolecular" (neuromolecular gaze), ou seja, a partir daí passou a haver certa predominância da abordagem molecular nos estudos sobre o cérebro.

Apesar de que há muito tempo não se aceita mais a ideia de faculdades mentais e sua localização no cérebro, tal como foi proposta por Gall e Spurzheim, a premissa de que processos psicológicos isolados podem ser localizados no cérebro compreende uma parcela considerável das neurociências contemporâneas. De acordo com Uttal (2001), a ideia geral foi resgatada na forma de uma hipótese moderna da localização de faculdades mentais no cérebro. Ainda que estudiosos falem de muitos processos da mente (percepções, emoções, sentimentos, atitudes, memórias, dentre outros), definir tais processos lógica e empiricamente não é tão simples ou direto como determinar regiōes cerebrais especializadas, tais como as regiōes cerebrais responsáveis pela visão ou por determinados movimentos corporais. 
Dessa forma, nosso objetivo é refletir sobre alguns aspectos das neurociências e discutir de que forma essa ciência pode ser, em certas situaçóes, fortemente reducionista, como ocorre no caso aqui analisado do Transtorno de Déficit de Atenção com Hiperatividade (TDAH). Para isso, primeiramente apresentamos alguns conceitos relacionados ao reducionismo e ao determinismo biológico, principalmente neurogenético. Por fim, propomos uma discussão sobre o caso das neurociências no TDAH.

Existem, atualmente, muitas críticas em relação ao diagnóstico do TDAH. Aquelas que o descrevem como resultado de um processo de medicalização infantil, ou do sofrimento, são as mais conhecidas (CONRAD, 2007; CONRAD; SCHNEIDER, 1992; TIMIMI, 2002), e existem desde a década de 1970 (CONRAD, 1975). O que pretendemos discutir neste artigo se relaciona a um outro tipo de crítica, que tem a ver com a medicalização, porém é mais específica aos aspectos biológicos da etiologia descrita na literatura científica do TDAH. Nosso argumento vai ao encontro dos conceitos e afirmações do reducionismo biológico desenvolvidos por Steven Rose. Nesse sentido, questionamos a ideia de que o TDAH é um transtorno biológico, que pode ser identificado por meio de técnicas de neuroimagem e que é tratável por meio de psicoestimulantes como o metilfenidato. Para essa análise, utilizamos três artigos científicos da revista The American Journal of Psychiatry, publicada pela Associação Americana de Psiquiatria (APA - American Psychiatric Association), responsável também pela publicação do DSM (Manual Diagnóstico e Estatístico de Transtornos Mentais, Diagnostic and Statistical Manual of Mental Disorders): Levy (1959), Faraone et al. (2001) e Peterson et al. (2009).

Levy (1959), no final da década de 1950, destaca possíveis causas orgânicas por trás de problemas de comportamento em crianças. $\mathrm{O}$ artigo é bastante relevante, pois apresenta dois tipos de discurso em torno de crianças com problemas de comportamento: (1) discurso em que as causas dos problemas estão no meio social, explicação mais comum na década de 50; (2) discurso biológico, alertando para possíveis causas orgânicas para os distúrbios de conduta, baseado em conclusões tiradas a partir do uso de medicamentos e na resposta positiva deles sobre o comportamento infantil. Peterson et al. (2009) examinaram o efeito de psicoestimulantes na atividade cerebral de crianças e adolescentes com TDAH e Faraone et al. (2001) realizaram uma metanálise 
dos estudos genéticos sobre o TDAH. Os dois últimos artigos representam o discurso hegemônico dos estudos de neuroimagem e genética em relação ao TDAH atualmente. O referencial para essa análise consiste, principalmente, na sequência redutiva proposta por Steven Rose (2001).

\section{O reducionismo e o determinismo neurogenético}

Chama-se reducionismo a ideia de que todas as coisas e objetos complexos e aparentemente diferentes que observamos no mundo podem ser explicados em termos de princípios universais que regem seus componentes fundamentais comuns (NAGEL, 1998). De uma forma geral, os reducionistas tentam explicar as propriedades de conjuntos complexos (como moléculas ou a sociedade, por exemplo), em termos das unidades que compõem essas moléculas ou sociedade.

O debate contemporâneo sobre o reducionismo ganhou força com Ernest Nagel (1961), citado como um dos principais autores do positivismo lógico. Segundo ele, redução "[...] é a explicação de uma teoria ou um conjunto de leis experimentais estabelecidas em uma área de pesquisa, por uma teoria geralmente, embora não invariavelmente, formulada para algum outro domínio” (p. 338). Outros autores clássicos que também discutem o tema são Feyerabend (1962) e Schaffner (1967), porém não entraremos em detalhes neste artigo.

Vamos nos deter aqui à descrição de Dobzhansky, Ayala, Stebbins et al. (1980) sobre três tipos de reducionismo: um ontológico, um metodológico e um epistemológico. O campo ontológico está relacionado, em biologia, à estrutura dos seres vivos. A questão é se as entidades e processos físico-químicos são subjacentes a todos os fenômenos vivos. $\mathrm{O}$ reducionismo ontológico afirma que os organismos são compostos de partes não vivas e que as leis da física e da química são as que regem os processos biológicos ao nível de átomos e moléculas. Entretanto, não sustenta que, necessariamente, os organismos são unicamente átomos e moléculas, trata apenas da origem, da formação dos seres vivos. Este tipo de redução encara a ciência como uma coisa unitária, sendo que a física é considerada a ciência mais fundamental (ROSE, 1998).

$\mathrm{O}$ reducionismo metodológico refere-se à estratégia de investigação e de aquisição de conhecimentos. Consiste em estudar o todo a partir das suas partes, procedimento bastante comum em pesquisa. Sustenta que os fenômenos vivos são mais bem estudados através dos menores níveis de complexidade possíveis. 
É mais fácil entender um fenômeno se podemos isolá-lo do resto do mundo e controlar as possíveis interferências de variáveis (ROSE, 1998). Uma versão mais radical do reducionismo metodológico afirma que todos os fenômenos biológicos podem ser compreendidos a nível molecular e atômico e só as investigações de processos e componentes físico-químicos são válidas. Já a visão moderada do reducionismo metodológico dá ênfase ao fato de que a compreensão dos processos vivos apresenta um avanço notável se os processos adjacentes a eles são conhecidos. Mas não justifica uma demanda de que sempre se deve investigar níveis cada vez menores. $\mathrm{O}$ único critério para a validade de qualquer investigação é o seu êxito. A metodologia reducionista, para uma melhor compreensão do fenômeno investigado, pode ser complementada por meio de outra metodologia que veja esse fenômeno de forma mais ampla e complexa.

Por exemplo, em uma visão estritamente biológica, o ser humano é um ser corporal e, por essa razão, deve ser metodologicamente reduzido ao seu corpo ou a partes de seu corpo (genes, aminoácidos, enzimas, órgãos, neurotransmissores, sinapses). Os estudos científicos em biologia devem eliminar, em nome do rigor metodológico, o social. Na falta dessa eliminação, não é possível obter resultados confiáves, fazer correlações estatísticas ou testar hipóteses (EHRENBERG, 2009).

Por fim, existe ainda o reducionismo epistemológico, teórico ou explicativo. A redução epistemológica de um ramo da ciência a outro se produz quando se considera que as teorias ou leis experimentais de um são casos especiais das teorias e leis formuladas em outro. "A integração de diversas teorias e leis científicas em outras mais amplas simplifica a ciência e amplia o poder explicativo dos princípios científicos, ajustando-se deste modo aos fins perseguidos pela ciência” (DOBZHANSKY; AYALA; STEBBINS et al., 1980, p. 490). A questão fundamental do reducionismo epistemológico, de acordo com Dobzhansky, Ayala, Stebbins et al. (1980) consiste em se as teorias e leis da biologia, por exemplo, podem ser reduzidas às leis da física e da química. Podemos perguntar se as leis e teorias que explicam o comportamento de sistemas complexos podem ser deduzidas como consequências lógicas a partir de leis e teorias que explicam o comportamento de seus componentes.

O reducionismo ao qual nos referimos, na questão das neurociências, é o epistemológico. E a discussão que propomos é sobre a tendência em insistir na explicação reducionista sobre qualquer outra, ou melhor, explicar aspectos muito 
complexos da conduta e organização social, mais especificamente humana, por meio de suas partes, fragmentos, e reduzi-los a essas partes ou fragmentos.

Para tornar o conceito de reducionismo epistemológico mais aplicado ao caso que nos propomos a discutir, podemos reconstruir o raciocínio reducionista praticado por alguns neurocientisas do seguinte modo: há muito se conhecem regiōes cerebrais responsáveis por fenômenos motores e sensoriais. É possível observar esses fenômenos por meio de técnicas de neuroimagem. Quando processos mentais ou comportamentos são analisados por meio dessas mesmas técnicas, é possível observar alterações funcionais, dependendo do estímulo oferecido. Portanto, pode-se pensar que processos mentais e comportamentos também podem ser localizados em regiōes cerebrais.

Para Ehrenberg (2009), muitas especulações biológicas sobre a mente, ou sobre a relação cérebro/mente, vão além do reducionismo metodológico, necessário em estudos científicos, chegando ao que o autor chama de "cegueira conceitual", na qual o ator das operaçôes mentais se resume aos mecanismos cerebrais. Isso sugere que o que está por trás dessas especulações é o reducionismo epistemológico, postura que Lewontin, Rose e Kamin (2003) chamam de determinismo biológico.

As explicações reducionistas, ou deterministas, quando falamos de neurociências, estão relacionadas às funções cerebrais, regióes cerebrais, neurotransmissores, neurônios, genes, dentre outros. Lewontin, Rose e Kamin, por serem genetecistas, referem-se mais especificamente a um tipo de reducionismo, o determinismo genético, mas ressaltamos que essa não é a única forma de explicação reducionista encontrada nos discursos das neurociências. De acordo com esses autores (LEWONTIN; ROSE; KAMIN, 2003), os deterministas biológicos que, por sua vez, são reducionistas, afirmam que a vida e as ações humanas são consequências inevitáveis das propriedades bioquímicas das células que constituem o indivíduo e que estas características estão determinadas, por sua vez, pelos constituintes dos genes que cada indivíduo possui.

Em relação à genética, fala-se do descobrimento de genes não só para doenças como câncer de mama, mas também para comportamentos ou situações sociais, tais como homossexualidade, alcoolismo, criminalidade e até problemas sociais muito complexos, como a falta de moradia (ROSE, 2001). Como a falta de moradia, um problema social complexo, pode ser reduzido a um gene ou a um grupo de genes? 
O determinismo biológico tem sido um meio poderoso para explicar as desigualdades sociais, riquezas e poder observadas nas sociedades capitalistas industriais contemporâneas e definir os universais humanos de comportamento como características naturais das sociedades. Assim, é fácil considerar que, se as desigualdades são determinadas biologicamente, então elas são inevitáveis e imutáveis (LEWONTIN; ROSE; KAMIN, 2003).

A síntese entre genética e as ciências neurológicas (chamada neurogenética) oferece a possibilidade de identificar os genes que afetam o cérebro e a conduta, atribuir-lhes poder causal e, se possível, modificar esses genes. Para Rose (2001), a neurogenética se diz capaz de responder a pergunta: "onde devemos buscar as explicações para nossas condições sociais e como modificá-las?”. Os reducionistas afirmam que o social tem sua importância mas, em últimos casos, os determinantes são biológicos. Assim, há os conhecimentos para intervir nos processos biológicos por meio de fármacos ou terapia genética.

Ehrenberg (2009) afirma que "[a]s razões sociais do sucesso popular das neurociências estão menos relacionadas a seus resultados científicos e práticos do que ao estilo de resposta dada para os problemas formulados pelo nosso ideal de autonomia individual generalizada” (p. 202). Segundo o autor, elas permitem consolar os que têm dificuldades para encarar o mundo de decisão e ação que evoluiu a partir da sociedade da disciplina (aquela que impunha o respeito à autoridade). Além disso, as neurociências dão esperança de que sejam disponibilizadas a todos técnicas de otimização das capacidades cognitivas e de controle emocional, também indispensáveis ao estilo de vida contemporâneo.

Segundo Rose (2001), todos gostariam de descobrir as origens de nossos fracassos, êxitos, vícios, crises, etc. Podemos buscar essas origens na sociedade, tais como estrutura social, economia, legislação; ou então na ordem pessoal, psicológica. Ou então podemos pensar no fator biológico e dizer que a raiz dos nossos problemas se encontra no cérebro, em sua bioquímica ou sua genética. Se for assim, devemos voltar nossos esforços para as neurociências em busca de explicações e para a farmacologia e a engenharia molecular, para falar nas soluções. É essa situação que o autor chama de reducionismo como ideologia.

Rose (2001) apresenta ainda uma sequência redutora defeituosa para o determinismo neurogenético, que inclui: objetivação, aglomeração arbitrária, quantificação improcedente, crença na normalidade estatística, localização 
ilegítima, causalidade fora de lugar, classificação dicotômica de causas genéticas e ambientais e a confusão de metáfora com homologia. O autor apresenta esses passos para alguns assuntos específicos, como inteligência, sexualidade ou violência, que servem de base para seus estudos. Porém, tentaremos, na seção seguinte, aplicá-los ao TDAH.

A objetivação converte um processo dinâmico em um fenômeno estático. Já a aglomeração arbitrária é uma extensão da objetivação, reunindo processos diferentes em uma única classificação. Assim como a aglomeração reúne atividades diversas, um mesmo ato ou fenômeno é socialmente aceitável ou não segundo as circunstâncias em que ocorre.

A quantificação improcedente sustenta que se podem dar valores numéricos aos caracteres objetivados e aglomerados, tornando possível a comparação entre indivíduos. Este postulado reflete a crença de que matematizar algo é apreendêlo e controlá-lo. A crença na normalidade estatística supõe que, numa população, a distribuição dos pontos contados de alguma característica tem a forma da chamada distribuição gaussiana ou distribuição normal. No sentido estatístico, normal descreve uma forma particular de curva que possui a propriedade de 95\% de sua área se encontrar a uma determinada distância da média. Porém, a qualificação não fica apenas nas análises estatísticas; ela tem uma característica normativa: ficar distante do que é considerado normal, em uma distribuição gaussiana, significa ser anormal.

Outra característica do reducionismo neurogenético, para Rose (2001), é a localização ilegitima, na qual o processo objetivado e quantificado deixa de ser propriedade do indivíduo e passa a ser propriedade de uma parte desse indivíduo. Diferentemente da frenologia e da época dos anatomistas, a localização hoje não está representada apenas por uma estrutura cerebral, mas por anormalidades em substâncias químicas do cérebro (neurotransmissores, enzimas ou genes responsáveis por sua produção).

A causalidade fora de lugar relaciona-se ao argumento recente de que um desequilíbrio em alguma molécula ou grupo de moléculas seria a causa subjacente de determinada conduta relacionada a essa molécula, geralmente tratada com algum fármaco que age nela. Em outras palavras, dizer que um desequilíbrio em um neurotransmissor é a causa de determinada conduta ou comportamento é equivocar a correlação e talvez até mesmo tomar a consequência pela causa. 
Não se pode afirmar se o desequilíbrio nos neurotransmissores é a causa ou a consequência de uma conduta considerada anormal. Até porque, geralmente, esse desequilíbrio é observado a partir do mecanismo de ação do psicofármaco utilizado para tratar aquela condição. Então, se a fluoxetina, por exemplo, age aumentando a recaptação de serotonina na fenda sináptica e tem resultado no tratamento da depressão, considera-se que a própria depressão é causada pela falta desse neurotransmissor. Essa causalidade invertida é uma das características da petite biologie, ou biologia menor, que, segundo Pignarre (2001), é o tipo de biologia que se utiliza para a pesquisa de novos fármacos em psiquiatria.

Se determinadas condutas são causadas por uma anormalidade na estrutura cerebral ou bioquímica ou por um desequilíbrio hormonal, quais são, por sua vez, as causas dessa anormalidade ou desequilíbrio? Poderíamos dizer que as causas são devidas ao meio ou à alimentação, dentre outras; porém, atualmente, fala-se com frequência nos genes, possibilitando os estudos de herdabilidade. Isso é o que Rose (2001) chama de classificação dicotômica.

Mesmo o comportamento mais trivial, para o qual a estatística não conseguiu encontrar um gene que o explique, é justificado por meio da herdabilidade. As novas técnicas estatísticas empregadas atualmente auxiliam a mostrar que as condições para as quais não se encontra um componente genético específico, são de fato resultantes de um efeito aditivo de muitos genes de pouco resultado.

Por fim, a confusão de metáfora com homologia tem a ver com a busca por equivalentes da conduta humana no mundo animal, em outras palavras, encontrar um modelo animal cuja conduta se possa controlar, manipular e quantificar mais facilmente. Dessa forma, se é descoberta alguma região do cérebro, ou neurotransmissores, ou genes, responsáveis por determinados comportamentos nos animais, rapidamente se pensa que então devem existir regiōes cerebrais, neurotransmissores ou genes similares ou idênticos nos seres humanos relacionados à patologia em questão.

John Bickle (2006) faz uma crítica aos debates sobre reducionismo em neurociências, argumentando que, muitas vezes, os resultados mais recentes das pesquisas neurocientíficas são ignorados. Propõe um modelo diferente para a redução em neurociências, o que ele chama de "intervir celularmente e acompanhar comportamentalmente”, defendendo que é possível, hoje, modificar uma molécula do cérebro, por exemplo, e observar os efeitos em termos de 
comportamento. Porém admite não ser possível praticar essa redução em campos da neurociência nos quais os mecanismos moleculares são ainda obscuros.

Procuramos refletir aqui sobre alguns aspectos das neurociências que podem estar criando explicaçóes reducionistas para problemas muito mais complexos do que conexóes neurais ou déficits em neurotransmissores. A seguir, propomos uma análise sobre o discurso científico em torno do TDAH e das neurociências, estudos de neuroimagem e determinismo neurogenético.

\section{Neurociência e comportamento infantil}

O TDAH é um transtorno caracterizado por dificuldade em manter a atenção em algumas atividades, acompanhado ou não de hiperatividade. Explica-se sua ocorrência, frequentemente, por um desequilíbrio em neurotransmissores cerebrais, especialmente a dopamina, e há uma busca constante por um componente genético. Nesse caso, poderíamos falar que ocorre um tipo de redução epistemológica?

Estudos estimam que o TDAH ocorra em 3\% a 5\% das crianças em idade escolar, correspondendo a, aproximadamente, 30\% a 50\% das crianças atendidas

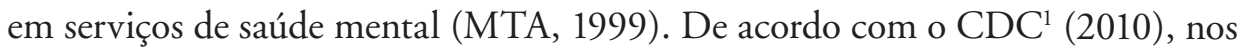
Estados Unidos, a porcentagem de crianças de 4 a 17 anos já diagnosticadas com TDAH aumentou de 7,8\% para 9,5\% entre 2003 e 2007, representando um aumento de 21,8\% em quatro anos. Entre os meninos, a prevalência de TDAH foi ainda maior, 13,2\% em 2007. Entre as crianças com TDAH, 66,3\% tomam medicação, totalizando $4,8 \%$ de todas as crianças entre quatro e 17 anos (aproximadamente 2,7 milhões). No Brasil, alguns estudos que utilizaram critérios da quarta edição do Manual Diagnóstico e Estatístico de Doenças Mentais - DSM-IV (APA, 1994), revelaram prevalências distintas do TDAH em escolares, variando de 5,8 a 17,1\% (PASTURA; MATTOS; ARAUJO, 2007).

Pensando na sequência redutora proposta por Rose (2001), observamos que, a partir da objetivação e da aglomeração arbitrária, foram criados os critérios diagnósticos para o TDAH. O conjunto de sintomas é bastante heterogêneo, caracterizando a reunião de processos diferentes em uma única classificação. Características de personalidade diversas, tais como cometer erros por descuido em atividades escolares, ter dificuldades para manter a atenção, ter dificuldade para organizar tarefas e atividades, falar em demasia, agitar mãos ou pés na 
cadeira, ter dificuldades em esperar sua vez, dentre outras constantes do DSMIV, foram transformadas em sintomas médicos.

A quantificação improcedente ainda não é tão disseminada em casos de TDAH. A avaliação diagnóstica ainda é feita de forma qualitativa, por meio de relatos dos professores e pais. Mas existem instrumentos que buscam a quantificação dos sintomas, para comparar entre indivíduos como, por exemplo, o questionário de Conners. Este foi elaborado na Austrália em 1969 e, posteriormente, revisado e abreviado em 1973. Existe uma versão para ser aplicada em pais e outra em professores, para avaliação de crianças com TDAH, principalmente do tipo hiperativo. É muito usado atualmente em estudos clínicos e epidemiológicos, sendo composto de várias perguntas que pais e/ou professores devem atribuir um número que vai de 0 a 4 (ZENTALL; BARACK, 1979). Ao final, as somas das respostas são contabilizadas e comparadas, tanto temporalmente (o resultado de um teste comparado com o resultado de outro teste da mesma criança) ou entre as crianças. Acredita-se, desse modo, ter mais confiabilidade e comparabilidade do que apenas o relato de pais, professores e das próprias crianças (que geralmente não são ouvidas).

Até a década de 1950, havia certa predominância de explicações sociais e psicológicas para os desvios de comportamento infantil, como afirma Levy (1959), quando descreve crianças com transtorno do comportamento pósencefalítico, entidade nosológica considerada como uma das "precursoras" do TDAH. Nessa época, tanto etiologia quanto tratamento em psiquiatria infantil eram geralmente psicodinâmicos. $\mathrm{O}$ autor chama a atenção para uma tendência em encontrar explicações orgânicas para essas condutas desviantes. Dessa forma,

Assim como nas psicoses maiores, onde, atualmente, estamos olhando novamente, cada vez mais, para causas biológicas e desconsiderando como causas básicas as influências psicológicas, talvez seja bom fazer o mesmo com os problemas de comportamento e a delinquência juvenil. (LEVY, 1959, p. 1063)

Levy ainda complementa afirmando que, se essas abordagens estiverem certas, os problemas de comportamento e a delinquência deveriam diminuir mais do que aumentar, como ocorreu "[...] em condições puramente físicas tais como tuberculose e pólio” (LEVY, 1959, p. 1063). Essas explicaçôes indicam vontade de encontrar um ou mais agentes causais para os problemas de comportamento, como aconteceu com a tuberculose e a pólio, para utilizar os exemplos do autor, e poder "exterminar" esse desvio do cérebro da criança 
da mesma forma que, utilizando um antibiótico, podemos matar o bacilo de Koch, agente causal da tuberculose. ${ }^{2}$

Se analisarmos a previsão de Levy, podemos perceber que essa comparação não é possível. Existem diferenças entre essas estruturas explicativas. A explicação etiológica construída para uma doença infecciosa é muito diferente da que é construída para a depressão ou outra doença da mente ou um comportamento. No caso da doença infecciosa, exames microbiológicos e anatomopatológicos, além de confirmarem o diagnóstico, podem indicar a terapêutica mais eficaz (BRZOZOWSKI; BRZOZOWSKI; CAPONI, 2010; CAPONI, 2009).

Ian Hacking (1999) sugere que algumas doenças mentais, como esquizofrenia ou autismo, e aqui acrescentamos o TDAH, têm um componente interativo. Isso quer dizer que o diagnóstico interage com a pessoa classificada, porque o componente interativo está relacionado com um papel social. Dessa forma, Hacking afirma que em uma classificação há dois tipos de elementos que podem estar associados com a doença: (1) a etiologia e as explicações biológicas; e (2) o comportamento do paciente e seu entorno social.

Quando a classificação, ou diagnóstico, tem uma etiologia definida e um marcador biológico, como na maior parte das doenças infecciosas, principalmente as de curta duração, como faringite ${ }^{3}$ por exemplo, não há um elemento interativo. Entretanto, quando as causas etiológicas não são tão evidentes, como nas doenças mentais, que envolvem comportamentos e julgamentos sociais, há um elemento interativo. Nesses casos, as pessoas classificadas podem mudar em razão do diagnóstico e das interações que resultam desse diagnóstico. Levy (1959) afirma que, se a hipótese de causa orgânica para os problemas de comportamento e a delinquência estiverem corretas, haveria uma diminuição de casos a partir do tratamento adequado dessas crianças. Poderíamos afirmar, no entanto, que isso também ainda não ocorreu.

O consumo global do metilfenidato, o principal fármaco utilizado no tratamento do TDAH, no período de 2003 a 2007, foi de 28,5 toneladas. Os Estados Unidos é o maior produtor e o maior consumidor do metilfenidato. No período entre 2005 a 2007, esse país consumiu uma média de 783 milhões de doses diárias $\left(\mathrm{S}-\mathrm{DDD}^{4}\right.$ ) de metilfenidato, o que corresponde a, aproximadamente, 77\% do consumo mundial dessa substância. No Brasil, em 2003, foram produzidos 86 Kg de metilfenidato. Já em 2007, essa produção subiu para $204 \mathrm{Kg}$ (ONU, 2008). 
Se o metilfenidato é o fármaco que combateria o problema cerebral responsável

pelo TDAH, era de se esperar que a prevalência do transtorno diminuísse com o tratamento. Porém, com o passar dos anos, com as mudanças nos critérios diagnósticos e difusão da informação sobre o transtorno, o número de crianças diagnosticadas e o consumo do metilfenidato vem aumentando. Além disso, o TDAH hoje é considerado uma condição crônica, que persiste na vida adulta em cerca de $70 \%$ a $80 \%$ dos casos (ROHDE; HALPERN, 2004).

A tentativa de localização cerebral das condutas, que Rose (2001) chama de localização ilegitima, se torna evidente ao analisarmos o discurso dos artigos científicos publicados sobre o TDAH como, por exemplo: "O tamanho do córtex pré-frontal lateral e dos córtices temporais anteriores estão bilateralmente reduzidos em crianças com TDAH [...]" (PETERSON et al., 2009, p. 1291).

A busca por medidas objetivas para o diagnóstico já era presente em 1959. Entretanto, nem exames físicos nem neurológicos davam resultados positivos. O eletroencefalograma (EEG) era comumente utilizado e não resultava em anormalidades específicas ou persistentes (LEVY, 1959). Até hoje, apesar de haver relativa certeza de que o TDAH é um transtorno biológico e que os medicamentos psicoestimulantes são o tratamento de primeira escolha, Peterson et al. (2009) admitem que o conhecimento sobre as bases neurais do tratamento ainda é limitado.

A maior parte desse conhecimento provém de estudos com modelos animais e estudos de tomografia em adultos, ambos com limitações quando falamos em extrapolação para o caso de crianças com TDAH. Pesquisas com exames de neuroimagem em crianças estudam um número pequeno de indivíduos com TDAH e os achados são bastante variados, envolvendo múltiplas regiões cerebrais na patofisiologia do transtorno como, por exemplo, vérmis do cerebelo, gânglios da base e córtex cerebral (PETERSON et al., 2009).

De acordo com Moysés e Collares (2010), é possível observar que cada localização é descrita por grupos de pesquisa diferentes, o que indica que talvez nenhum deles tenha encontrado algo muito concreto. Além disso, o número de sujeitos estudados ésempre muito pequeno, não há uma amostragem bem definida, não há grupo controle e nem preocupação em relatar como o diagnóstico foi feito. Ademais, segundo Leo e Cohen (2003), o grande problema da maior parte dos estudos de neuroimagem é que eles comparam crianças com TDAH (que 
geralmente tomam um medicamento estimulante) com crianças consideradas normais. Ainda que, em grande parte dos estudos realizados, a administração do metilfenidato tenha sido interrompida até 48 horas antes dos testes de neuroimagem, não há como ter certeza de que as diferenças encontradas estejam relacionadas com a patofisiologia do TDAH, e não com o metilfenidato. Isso só seria possível se fossem comparadas crianças que não tomam o medicamento com crianças que o utilizam.

Normalizar a criança com TDAH não significa somente ajustar seu comportamento para que ela se adapte ao meio em que vive. Trata-se de uma normalização biológica, como descrevem Peterson et al. (2009, p.1290):

Esses achados sugerem que os estimulantes melhoram os sintomas em jovens com TDAH normalizando a atividade dentro de uma rede dispersa de regióes do cérebro no córtex cingulado anterior e córtex cingulado posterior e melhorando as interações funcionais desse circuito com o córtex pré-frontal lateral.

A normalidade no TDAH não está tão vinculada à estatística, já que o diagnóstico geralmente não é quantificado, mas sim à normalidade dos comportamentos que, em última instância, seriam regulados pelo cérebro. A normalização biológica faria com que ocorresse melhora no comportamento, uma vez que os problemas de conduta teriam como causa subjacente alguma alteração biológica.

A biologia menor descrita por Pignarre (2001), na qual a explicação causal de um transtorno mental seria advinda, principalmente, do mecanismo de ação do tratamento farmacológico, que caracteriza a causalidade fora de lugar, é evidente no caso do TDAH:

Os estudos genéticos moleculares do TDAH estão focados nos genes das vias catecolaminérgicas por causa de modelos animais, de consideraçôes teóricas e da efetividade do tratamento estimulante, que implica uma disfunção catecolaminérgica na patofisiologia do transtorno. (FARAONE et al., 2001, p. 1052)

Muitas das afirmações em torno de uma etiologia biológica para o TDAH são postuladas a partir de modelos animais, o que pode levar à confusão de metáfora com homologia. Um exemplo de modelo animal utilizado para estudar o TDAH é o dos ratos espontanemente hipertensos, que são considerados como apresentando características comportamentais semelhantes aos aspectos fundamentais do transtorno (TAKAHASHI, 2006). 
A busca por um gene causador das modificações biológicas que são relacionadas

ao TDAH é constante, mas nenhum estudo encontrou associação consistente entre comportamento TDAH e um gene (FARAONE et al., 2001), como os próprios pesquisadores admitem. Como o mecanismo de ação dos estimulantes está relacionado com a dopamina, há uma busca por genes que tenham relação com essa via, tais como o DRD4, o gene do receptor D4 da dopamina. A busca pelos componentes genéticos como causa primária do TDAH exemplifica a classificação dicotômica descrita por Rose (2001).

Apesar dos resultados poucos sólidos, a explicação genética não é colocada em discussão. Dúvidas sobre as teorias atualmente aceitas não são colocadas em pauta. Pelo contrário, novos tipos de explicação biológica são encontrados para "driblar" esse tipo de percalço: se não é possível encontrar um gene que, em todos os casos de TDAH, seria a causa biológica dos problemas de comportamento, então o que causa o TDAH é a soma de vários genes de pouco efeito. Faraone et al. (2001, p.1052) chamam a atenção para o fato de que essa imprecisão genética é comum em psiquiatria, “[...] porque as doenças psiquiátricas são provavelmente mediadas por muitos genes agindo em conjunto, cada um desses genes individualmente exerce somente um efeito pequeno no transtorno". Mesmo quando se admite que o TDAH é um transtorno complexo, como no artigo de Faraone et al. (2001), ele é considerado complexo apenas no sentido biológico, sem nenhum outro fator envolvido.

\section{Considerações finais}

Para Rose (2005), de alguma forma a expansão das capacidades mentais, de nossos ancestrais unicelulares até hoje, se deu por meio da evolução não somente do cérebro, mas do cérebro no corpo e ambos na sociedade, cultura e história. E o autor ainda pergunta: até onde somos capazes de ir na relação entre a mente e o cérebro, ou na relação entre processos mentais e dinâmicos e processos neurais?

Segundo Pignarre (2001), a biologia utilizada na psiquiatria é uma biologia dos receptores bioquímicos, mais do que do cérebro. Fornece explicaçōes sobre os modos de ação dos psicotrópicos e ajuda a escolher novas moléculas, dentre as disponíveis nas quimiotecas da indústria farmacêutica, mas jamais pode dar uma explicação causal dos problemas mentais. Essa biologia, a petite biologie, tem 
pouca utilidade fora dos laboratórios dessas indústrias e trabalha para aperfeiçoar as ferramentas de seleção de novos psicotrópicos, que são sempre os penúltimos.

Os fenômenos da vida são complexos e sempre relacionados com o biológico e o social. Dessa forma, segundo Rose (2001), as explicações somente são adequadas quando levam em consideração essas duas dimensões. Lewontin, Rose e Kamin (2003) fazem uma crítica ao determinismo biológico, mas também rejeitam a ideia de um determinismo cultural, ou seja, a biologia vai até o nascimento do ser humano e, a partir de então, ele é moldado essencialmente por meio da cultura (visão também considerada reducionista). Os autores defendem uma compreensão integral das relações entre o biológico e o social, que eles chamam de compreensão dialética. As explicações dialéticas não separam as propriedades das partes isoladas das associações, quando formam conjuntos, mas consideram que as propriedades das partes surgem destas associações. Assim, de acordo com essa visão, as propriedades das partes e dos conjuntos se codeterminam mutuamente. As propriedades dos seres humanos individuais não se dão isoladamente, surgem como consequência da vida social, ainda que a natureza dessa vida social seja consequência, por sua vez, do fato de que somos seres humanos.

Segundo Rose (2001, p. 336)

Os motivos de semelhantes explicações reducionistas derivam em parte do poder do reducionismo como metodologia e filosofia, mas sobretudo da urgência para achar explicaçôes da magnitude dos transtornos sociais e pessoais nas sociedades industriais desenvolvidas no final do século XX, as que deslocam a "culpa" do político para o individual.

As explicações reducionistas, tomadas aqui através de um exemplo concreto, o TDAH, emergem como uma forma de tornar doença um comportamento indesejado socialmente. Elas proporcionam uma solução ao problema, pois se a causa de um comportamento é biológica, então ele pode ser tratado biologicamente, por meio de um medicamento. Além disso, o reducionismo epistemológico dificulta a reflexão, por parte dos próprios pesquisadores, sobre os fenômenos que se propõem a estudar. Não há discussão sobre as limitações das explicações apresentadas. Mesmo não encontrando um gene ou uma região responsável pelo comportamento TDAH, não se questiona a busca por esses "marcadores". Pelo contrário, não encontrar um marcador ilustra um fenômeno complexo, mas complexo biologicamente. Os problemas sociais são transferidos para o nível individual, no qual existe unicamente a pessoa doente, sem levar em conta os determinantes sociais. 
De acordo com Rose (2004), os medicamentos psiquiátricos são utilizados em meio a certas concepções do que os seres humanos são ou podem ser, ou seja, normas, valores, julgamentos específicos internalizados na ideia desses fármacos. Os diagnósticos psiquiátricos, assim como a constante administração dos riscos a que estamos expostos diariamente, em certo sentido passam por uma definição de moralidade. Essa normalização, a construção de si mesmo por meio de medicamentos é o que Rose (2004) chama de "self neuroquímico" (neurochemical self) e Dumit (2003) de selffarmacêutico (pharmaceutical self).

O que é possível perceber, por meio dos artigos analisados e da literatura apresentada, é que as explicaçōes biológicas para o TDAH desconsideram o meio social em que a criança vive. Isso quer dizer que, se há um problema de comportamento, levando em consideração somente a "causa biológica", com o consequente tratamento medicamentoso, perde-se a dimensão social e muitos fatores são desconsiderados, tais como violência, pobreza, subnutrição, dentre outros.

Não podemos negar a importância dos fatores biológicos na patofisiologia das doenças, e também não negamos que os transtornos psiquiátricos tenham um componente biológico envolvido. Mas como ter certeza de que esse componente é "a causa" do transtorno? Como afirmar que o meio social não tem influência no desequilíbrio dos neurotransmissores? Se for assim, se o meio social tiver influência no biológico, então somente administrando medicamentos estaríamos mascarando a tristeza e o sofrimento, causando um tipo de "anestesia psicológica".

Sobre o reducionismo proposto por Bickle (2006) para as neurociências, "intervir celularmente e acompanhar comportamentalmente", o autor cita experimentos in vitro e em animais que claramente conectam um mecanismo molecular a um comportamento específico, no caso a memória de longo prazo. Mas esses dados não podem ser diretamente extrapolados para os seres humanos, que possuem um sistema nervoso muito mais complexo. Além disso, a ideia de Bickle é que a redução é possível quando há um conhecimento avançado sobre o assunto em questão. O que observamos, no caso do TDAH, é uma lógica invertida: ao invés de conhecer os mecanismos envolvidos na atenção e na impulsividade, a explicação para o transtorno é buscada principalmente a partir da lógica explicativa do mecanismo de ação do medicamento que se utiliza para tratá-lo.

Sugerimos, dessa forma, que parte das neurociências utiliza explicações reducionistas para várias condições mentais classificadas como doenças. Assim, 
são utilizados exames de neuroimagem para comprovar, a partir do mecanismo de ação de um medicamento, uma classificação nosológica que possui, por sua vez, fragilidades epistemológicas. Apresentamos uma sequência redutora em que se inscreve o caso específico do TDAH, mas não podemos ir além no momento. Seria necessário avaliar os argumentos utilizados para classificar o TDAH como sendo uma doença psiquiátrica, para apontar tais fragilidades. Podemos, sim, sugerir certo cuidado ao generalizar e ter como certo explicaçóes sobre neurotransmissores, localização cerebral e genes no caso específico do TDAH. ${ }^{5}$

\section{Referências}

ABI-RACHED, J.; ROSE, N. The birth of the neuromolecular gaze. History of the human sciences, v.23, n.1, p.11-36. 2010.

AMERICAN PSYCHIATRIC ASSOCIATION. DSM-IV Diagnostic and Statistical Manual of Mental Disorders. 4. ed. Washington, DC: APA, 1994.

BRZOZOWSKI, F. S.; BRZOZOWSKI, J. A.; CAPONI, S. Classificações interativas: o caso do Transtorno de Déficit de Atenção com Hiperatividade infantil. Interface Comunicação, Saúde, Educação, v.14, n. 35, p. 2010.

CAPONI, S. O diagnóstico de depressão, a "petite biologie" e os modos de subjetivação. In: CAPONI, S. et al. (Org.). Medicalização da Vida: ética, saúde pública e indústria farmacêutica. Florianópolis: Unisul, 2009. p.135-143.

CENTERS FOR DISEASE CONTROL AND PREVENTION. Increasing Prevalence of Parent-Reported Attention-Deficit/Hyperactivity Disorder Among Children - United States, 2003 and 2007. MMWR Morbidity and Mortality Weekly Report, v.59, n.44, p.1439-43, 2010.

CONRAD, P. The discovery of hyperkinesis: notes on the medicalization of deviant behavior. Social Problems, v.23, n.1, p.12-21, 1975.

The medicalization of society: on the transformation of human conditions into treatable disorders. Baltimore: The Johns Hopkins University Press, 2007.

CONRAD, P.; SCHNEIDER, J.W. Deviance and medicalization: from badness to sickness. Philadelphia: Temple University Press, 1992. 327 p.

DOBZHANSKY, T. et al. Evolución. Barcelona: Omega, 1980.

DUMIT, J. Is it me or my brain? Depression and neuroscientific facts. Journal of Medical Humanities, v.24, n.1/2, p.35-47. 2003.

EHRENBERG, A. O sujeito cerebral. Psicologia Clínica, v.21, n.1, p.187-213. 2009.

FARAONE, S.V. et al. Meta-Analysis of the Association Between the 7-Repeat Allele of the Dopamine D4 Receptor Gene and Attention Deficit Hyperactivity Disorder. The American Journal of Psychiatry, v.158, p.1052-7. 2001. 
FEYERABEND, P. K. Explanation, reduction and empiricism. Minnesota Studies in the Philosophy of Science, v.3, p.28-97. 1962.

HACKING, I. The social construction of what? Cambridge: Harvard University Press, 1999.

LEO, J.; COHEN, D. Broken brains or flawed studies? A critical review of ADHD neuroimaging research. The Journal of Mind and Behavior, v.24, n.1, p.29-56. 2003.

LEVY, S. Post-encephalitic behavior disorder: a forgotten entity: a report of 100 cases. The American Journal of Psychiatry, v.115, n. 2, p.1062-7. 1959.

LEWONTIN, R.C.; ROSE, S.; KAMIN, L.J. No está en los genes: racismo, genética e ideología. Barcelona: Romanyà, 2003.

MOYSES, M.A.A.; COLLARES, C.A.L. Dislexia e TDAH: uma análise a partir da ciência médica. In: PAULO, C.R.D.P.D.S.; ESCOLAR, G.I.Q. (Org.). Medicalização de Crianças e Adolescentes: conflitos silenciados pela redução de questôes sociais a doenças de indivíduos. São Paulo: Casa do Psicólogo, 2010. p.71-110.

MTA. The MTA Cooperative Group. A 14-month randomized clinical trial of treatment strategies for attention-deficit/hyperactivity disorder. Archives of General Psychiatry, v.56, p.1073-1086. 1999.

NAGEL, E. The structure of science: Problems in the logic of scientific explanation. New York: Harcourt, Brace and World, 1961.

NAGEL, T. Reductionism and Antireductionism. In: BOCK, G.; GOODE, J. (Org.). The limits of reductionism in biology. Chichester: J. Wiley, 1998. p.3-14.

ONU. International Narcotics Control Board. International Narcotics Control Board. Psychotropic substances: statistics for 2007: assessments of annual medical and scientific requirement. 2008. Disponível em: http:/www.incb.org/pdf/technical-reports/ psychotropics/2008/psy_2008.pdf. Acesso em: 2 dez 2008.

PASTURA, G.; MATTOS, P.; ARAÚJO, A.P.D.Q.C. Prevalência do Transtorno do Déficit de Atenção e Hiperatividade e suas comorbidades em uma amostra de escolares. Arquivos de Neuropsiquiatria, v.65, n.4-A, p.1078-1083, 2007.

PETERSON, B.S. et al. An fMRI study of the effects os psychostimulants on default-mode processing during stroop task performance in youths with ADHD. The American Journal of Psychiatry, v.166, n.11, p.1286-94. 2009.

PIGNARRE, P. Comment la dépression est devenue une épidémie. Paris: Hachette Littératures, 2001. $153 \mathrm{p}$.

ROHDE, L.A.; HALPERN, R. Transtorno de déficit de atenção/hiperatividade. Jornal de Pediatria, v.80, n.2 (Sup.), p.S61-S70, 2004.

ROSE, N. Becoming Neurochemical Selves. In: STEHR; NICO (Org.). Biotechnology, commerce and civil society. Somerset: Transaction Publishers, 2004. p.89-128. 
ROSE, S. What is wrong with reductionist explanations of behaviour? In: BOCK, G. R.;GOODE, J. A. (Org.). The limits of reductionism in biology. New York: John Willey \& Sons, 1998. p.176-92.

. Trayectorias de vida: Biología, libertad, determinismo. Barcelona: Granica, 2001.

. The future of the brain: The Promise and Perils of Tomorrow's Neuroscience. New York: Oxford University Press, 2005. 344 p.

SCHAFFNER, K. Approaches to reduction. Philosophy of Science, v.34, p.137-47, 1967.

TAKAHASHI, R. N. Animais espontaneamente hipertensos (ratos SHR) como modelo experimental de TDAH. In: REUNIÃO ANUAL DA SBPC, 58. Anais... Florianópolis, SC v. n. 2006. Disponível em: http://www.sbpcnet.org.br/livro/58ra/atividades/TEXTOS/ texto_260.html. Acesso em: 4 abr 2011.

TIMIMI, S. Pathological child psychiatry and the medicalization of childhood. New York: Routledge, 2002. 190p.

UTTAL, W.R. The new phrenology: the limits of localizing cognitive processes in the brain. Cambridge: MIT Press, 2001. 255 p.

ZENTALL, S.S.; BARACK, R.S. Rating scales for Hyperactivity: concurrent validity, reliability, and decisions to label for the Conners and Davids Abbreviated Scales. Journal of Abnormal Child Psychology, v.7, n.2, p.179-190, 1979.

\section{Notas}

${ }^{1}$ Centers for Disease Control and Prevention (Centro para Controle e Prevenção de Doenças): órgão americano responsável pela prevenção e controle de doenças e danos.

${ }^{2}$ Ainda que o Mycobacterium tuberculosis, ou bacilo de Koch, não seja a única causa da tuberculose (muitas pessoas convivem com o microorganismo em seu corpo e nunca desenvolvem a doença, pois os fatores sociais são muito importantes), não há tuberculose sem a presença do bacilo. Ele seria uma causa necessária, mas não suficiente.

${ }^{3}$ Não podemos afirmar o mesmo de doenças crônicas, mesmo infecciosas, com etiologia bem definida, como é o caso do HIV e da hanseníase. Essas doenças são frequentemente alvos de preconceitos e estigmas sociais e possuem um elemento interativo, já que as pessoas acometidas se modificam em função do diagnóstico recebido.

${ }^{4}$ S-DDD (definer daily doses for statistical purposes, ou doses diárias definidas com fins estatísticos) é uma unidade técnica de medida desenvolvida para o uso de análises estatísticas e não representa, necessariamente, a dose prescrita. Isso porque os psicotrópicos podem ser usados para diferentes tratamentos, dependendo do país e suas práticas médicas. Para o metilfenidato, a S-DDD corresponde a $30 \mathrm{mg}$ diários (ONU, 2008).

${ }^{5}$ F. Brzozowski participou de todas as etapas da confecção do artigo. S. Caponi participou com contribuições teóricas, supervisão e revisão do texto. 
Biological determinism and neuroscience in the case of attention deficit disorder with hyperactivity

Our goal is to reflect how the neurosciences can be strongly reductionist when trying to explain behaviors based solely on brain processes, and use as an example the case of attention deficit disorder with hyperactivity (ADHD). The reductionism to which we refer, also called biological or neurogenetic determinism, the question of neuroscience, is the epistemological, ie one that tries to explain a complex problem for only some of its parts, ignoring other factors such as social and cultural. As ADHD is currently described as essentially a disease of the brain, we applied a model for defective reductive sequence neurogenetic determinism proposed by Steven Rose, which includes: objectification, arbitrary agglomeration, quantification unfounded belief in statistical normality, location illegitimate, causality outside place, dichotomous classification of genetic and environmental causes and confusion of metaphor with homology. Life is a complex phenomenon and is related to biological and social aspects. Thus, explanations are appropriate only when it takes into account these two aspects. We suggest, therefore, that some uses of neuroscience reductionist explanations for various conditions classified as mental illnesses, including ADHD.

> Key words: neuroscience; attention deficit disorder with hyperactivity; reductionism, biological determinism, neurogenetic determinism. 